Rheumatology, Santander, Spain; ${ }^{2}$ HUMV, Preventive Medicine, Santander, Spain: ${ }^{3}$ University of Cantabria, Santander, Spain

Background: Rheumatoid arthritis (RA) patients are at increased risk of severe infections due to the disease itself, and the immunosuppressive treatment. Vaccination programs are designed to decrease the risk of infections.

Objectives: In patients with RA treated with biologic therapy (BT) our aim was to assess a) the incidence of severe respiratory infections and b) to compare the risk between vaccinated and non vaccinated patients.

Methods: Observational study of 431 patients diagnosed with RA that iniciated BT. One group of patients participated in a vaccination program from October 2011 to October 2016 (Group 1). The other group was not included in the vaccination program (Group 2). The follow-up was made until June 2017 with a minimum follow-up period of 8 months and a maximum of 5.5 years.

Information on severe respiratory infections, defined as those that required hospitalization or at least one dose of intravenous antibiotic treatment at the emergency room, was retrieved from the hospital medical records.

Results: We studied 431 patients (335 women/96 men); mean age $63.4 \pm 13.7$ years. In the vaccination program (group 1) were included $299(69.37 \%)$ patients and in the group 2132 patients (30.63\%). The main features of both groups are summarized in Table 1.

During the follow-up, we registered 299 hospital admissions due to severe respiratory infections in both groups (incidence density 9.9 (95\% Cl: 6.9-13.6) In group 1, vaccinated patients, this incidence density was reduced to 7.1 (95\% Cl: 4.1-11.6). Figure 1.

The vaccination program reduced the general incidence of severe respiratory infection in $44 \%$.

Conclusion: RA patients with BT included in the vaccination program present a lower incidence of severe respiratory infections compared with non vaccinated patients.

Table 1. Main general features at BT onset

\begin{tabular}{|c|c|c|c|}
\hline & $\begin{array}{c}\text { Group } 1 \\
\text { Vaccination program } \\
\mathrm{N}=299\end{array}$ & $\begin{array}{c}\text { Group } 2 \\
\begin{array}{c}\text { Non vaccination } \\
\text { program }\end{array} \\
\mathrm{N}=132\end{array}$ & $\mathbf{p}$ \\
\hline Age (years) mean $\pm S D$ & $61.32 \pm 13.04$ & $67.97 \pm 14.17$ & 0.32 \\
\hline Women, $\mathrm{n}(\%)$ & $231(77.3 \%)$ & $105(79.5 \%)$ & 0.59 \\
\hline $\begin{array}{l}\text { Duration of RA (months) } \\
\text { mean } \pm S D\end{array}$ & $73.24 \pm 10.4$ & $112.62 \pm 60.2$ & \\
\hline Positive RF/ Positive ACPA, n (\%) & $177(59.2) / 172(57.52 \%)$ & $93(70.5 \%) 98(74.24 \%)$ & $0.02 / 0,01$ \\
\hline Erosive disease, $\mathrm{n}(\%)$ & $116(38.8 \%)$ & $70(53 \%)$ & 0.06 \\
\hline Vasculitis, n (\%) & $15(5 \%)$ & $2(1.5 \%)$ & 0.08 \\
\hline Interstitial lung disease $\mathrm{n}(\%)$ & $12(4 \%)$ & $7(5.3 \%)$ & 0.54 \\
\hline Subcutaneous nodules $\mathrm{n}(\%)$ & $16(5.4 \%)$ & $6(4.5 \%)$ & 0.72 \\
\hline Corticosteroids & $299(100 \%)$ & $132(100 \%)$ & 1 \\
\hline $\begin{array}{l}\text { Number of conventional DMARDs } \\
\text { mean } \pm \text { SD }\end{array}$ & $1.66 \pm 0.89$ & $2.03 \pm 1.05$ & 0.3 \\
\hline
\end{tabular}

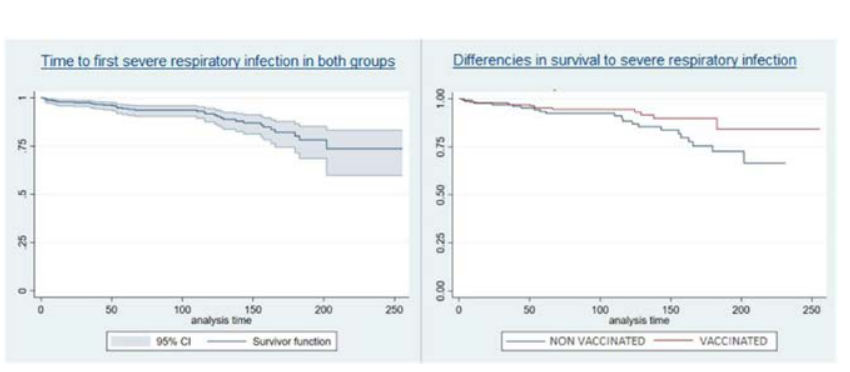

Figure 1.

Disclosure of Interests: None declared

DOI: 10.1136/annrheumdis-2021-eular.3180

\section{POS1468-HPR THE IMPACT OF COVID-19 ON RHEUMATOLOGY HEALTH CARE WORKERS AND THEIR SCIENTIFIC OUTPUT: HEAVY LIES THE CROWN ON FEMALE RHEUMATOLOGISTS}

C. Kirchler ${ }^{1}$, M. R. Andrews ${ }^{2}$, E. Mosor ${ }^{2}$, K. Thaler ${ }^{3}$, T. Stamm², R. FritschStork $^{1,3,4}$, C. Duftner ${ }^{5}{ }^{1}$ School of Medicine, Sigmund Freud University Vienna, Austria, Rheumatology, Vienna, Austria; ${ }^{2}$ Medical University of Vienna, Section for Outcomes Research, Center for Medical Statistics, Informatics, and Intelligent Systems, Vienna, Austria; ${ }^{3}$ Hanusch Hospital of the Austrian Health Insurance Fund, 1st Medical Department of Internal Medicine, Vienna, Austria; ${ }^{4}$ Ludwig Boltzmann Institute of Osteology, Hanusch Hospital and AUVA Trauma Center Meidling, Vienna, Austria; ${ }^{5}$ Medical University Innsbruck, Clinical Division of Internal Medicine II, Innsbruck, Austria

Background: COVID-19 has changed daily practice in medicine and affected teaching as well as research activities of medical personnel. Meanwhile, the pandemic's impact on private life and responsibilities for dependents also affected health care workers in rheumatology.

Objectives: To examine the adaptability of clinician-researchers in rheumatology in a time of crisis focusing on academic output in the first six months of the COVID-19 pandemic and to investigate the professional and private burden experienced by health care workers in rheumatology.

Methods: A systematic search in PubMed, medRxiv and bioRxiv for reports of rheumatic diseases and COVID-19/SARS-CoV-2 submitted (or published) from January 1 to June 302020 was carried out. As comparison, publications from April 6 to 132019 of the same rheumatic diseases without COVID-19 were analysed in terms of author characteristics and journal metrics. Additionally, a questionnaire was circulated via EULAR countries rheumatology societies and individual working group members. The participants were asked to answer 43 questions regarding their family situation, professional background, research output, changes in work and private responsibilities during the pandemic as well as the burden experienced. Responses were collected using an online survey tool and data analyses performed with SPSS Statistics 25; missing variable analysis was performed, excluding records with $>15 \%$ missing responses. Descriptive and summary statistics were calculated for the entire dataset and split by gender.

Results: Whereas the overall number of publications and authors was equal between 2020 and 2019, the portion of female first authors of review articles and original studies decreased substantially in the first phase of the pandemic (Table 1). The numerical contribution of female authors in highly ranked journals (impact factor>6) was comparable in 2019 and 2020 however, the percentage of female first authors dropped from $50 \%$ to $32 \%$ $(P=0.07)$.

Table 1. Author and journal metrics of publications

\begin{tabular}{|c|c|c|c|}
\hline \multicolumn{4}{|c|}{ Authors } \\
\hline & 2019 (\%) & $2020(\%)$ & \\
\hline Proportion female & $N=1386$ & $\mathrm{~N}=1361$ & P-value \\
\hline $\begin{array}{l}\text { overall } \\
\text { first authorships }\end{array}$ & 46,8 & 41.1 & n.s. \\
\hline all publications & 46,8 & 35,3 & 0.021 \\
\hline reviews & 56,7 & 30 & n.s. \\
\hline original studies & 46,2 & 18,2 & 0.004 \\
\hline other reports* & 42,6 & 39,9 & n.s. \\
\hline \multicolumn{4}{|l|}{ last authorships } \\
\hline all publications & 34,7 & 27,9 & n.s. \\
\hline reviews & 33,3 & 15 & n.s. \\
\hline original studies & 32,1 & 30,3 & n.s. \\
\hline other reports* & 40,7 & 29,1 & n.s. \\
\hline
\end{tabular}

In the survey, a total dataset was available for $\mathrm{N}=180$ responders. On average, female respondents $(52.5 \%)$ were younger, more likely to live alone $(19,1 \%$ vs $10,5 \%)$ and have no caring responsibilities $(51.1 \%$ vs. $36.3 \%)$ than male respondents.

Male doctors were more often tenure-track/tenured or chairmen (31.4\% vs $12.8 \%$ female) and worked less often part-time ( $9,3 \%$ vs. $19.1 \%)$. Unpaid overtime hours of all participants were striking with $46.3 / 44,2 \%$ (female/male) reporting to accumulate $>10$ hours/ week.

Regarding gender differences in scientific output, male respondents more frequently revealed $>20$ publications as first $(57,6 \%$ vs. $26,9 \%)$ or last authors (34.1\% vs. $10,1 \%$ ). Similarly, $44,7 \%$ of male respondents reported a last author publication during COVID-19 vs. $26,4 \%$ of female respondents.

While female and male respondents reported similar experience of burden during the pandemic, more female respondents reported increased family care as a major source of this $(38,2 \%$ vs. $22,2 \%)$. Both genders would like to see increased support from superiors and official institutions. 
Conclusion: In a time of acute crisis, the adaptability of scientifically active female health care workers in rheumatology is lower than that of their male counterparts. This is reflected in a lower scientific output, especially as first or last authors. However, the burden experienced in the current pandemic is similar between the genders.

Disclosure of Interests: None declared

DOI: 10.1136/annrheumdis-2021-eular.3586

\section{POS1469-HPR THE ASSESSMENT OF FRACTURE RISK AND OSTEOPOROSIS RATE AMONG PATIENTS OVER 50 YEARS OLD UNDERGOING MEDICAL REHABILITATION}

\section{Marchenkova ${ }^{1} .{ }^{1}$ National Medical Research Center for Rehabilitation and Balneology of Ministry of Health of Russian Federation, Rehabilitation Department for Somatic Patients, Moscow, Russian Federation}

Background: Taking a course of physical rehabilitation creates the prerequisites for falls and injuries in patients at high risk of fractures. Data on fracture risk and prevalence of osteoporosis in older patients starting medical rehabilitation can change the approach of doctors to the development of rehabilitation programs and the management of such patients.

Objectives: To assess the prevalence of osteoporosis, individual risk factors for osteoporosis as well as the proportion of people with high risk of osteoporotic low-energy fractures among patients over 50 years old undergoing treatment according to the "medical rehabilitation" profile.

Methods: The study group comprised of 600 patients (426 women and 174 men) aged 50 to 84 years, average age $64.25 \pm 10.17$ years, undergoing treatment in a rehabilitation department. This was a cross-sectional study in the form of unified questionnaire, including data concerning age, weight, height, $\mathrm{BMI}$, clinical and rehabilitation diagnosis, anamnesis of the main disease, anamnesis vitae, presence of osteoporosis diagnosis in the anamnesis, its treatment, osteoporosis risk factors estimation. An assessment of 10-year probability of osteoporotic fractures was carried out using Russian model of online FRAX® calculator.

Results: $41.8 \%$ patients in the study sample had osteoporosis risk factors, including $31.2 \%$ of subjects had 3 risk factors or more. $38.0 \%$ patients showed a high fracture risk according to the FRAX calculator. $34.1 \%$ had a diagnosis of osteoporosis, and $45.8 \%$ already had osteoporotic fractures. Among those who did not undergo densitometry examination, $69.9 \%$ had a history of low-traumatic fractures, and only $58.5 \%$ of patients with an established diagnosis of osteoporosis and $26.8 \%$ of those at high risk of fractures received effective therapy for osteoporosis.

Conclusion: Population of patients over 50 years old undergoing rehabilitation is characterized by high frequency of osteoporosis and probability of fractures, and insufficient quality of osteoporosis verification and anti-osteoporotic therapy administration at the same time.

Disclosure of Interests: None declared

DOI: 10.1136/annrheumdis-2021-eular.4258 HPR Interventions (educational, physical, social
and psychological)

\section{POS1470-HPR BARRIERS AND FACILITATORS OF A NEW MODEL OF STRATIFIED EXERCISE THERAPY IN KNEE OSTEOARTHRITIS: A QUALITATIVE STUDY}

J. Knoop ${ }^{1}$, W. Van Berkel-de Joode ${ }^{1}$, H. Brandt ${ }^{1}$, J. Dekker ${ }^{2}$, R. Ostelo ${ }^{1} .{ }^{1}$ Vrije Universiteit Amsterdam, Health Sciences, Amsterdam, Netherlands; ${ }^{2}$ Amsterdam UMC (VUmc), Department of Rehabilitation, Amsterdam, Netherlands

Background: We have developed a model of stratified exercise therapy, in which three knee osteoarthritis $(\mathrm{OA})$ subgroups (i.e., 'high muscle strength subgroup', 'low muscle strength subgroup' and 'obesity subgroup') can be distinguished and provided a subgroup-specific intervention. Currently, the (cost-)effectiveness of this model compared to usual exercise therapy is tested in a large-scaled randomized controlled trial (OCTOPuS-study [1]). Alongside this trial, we performed a qualitative study to explore perceived barriers and facilitators of the application of this model in primary care.

Objectives: To explore barriers and facilitators of the application of this model in primary care, as perceived by patients, physiotherapists and dieticians.

Methods: Qualitative data were collected through semi-structured interviews in a random sample of 15 patients ( 5 from each subgroup), 11 physiotherapists and 5 dieticians, from the experimental arm of the OCTUPuS trial. A thematic analysis of the data was performed.

Results: We identified 14 themes in 5 categories. In general, patients and therapists were positive about the added value and applicability of the model, although some physiotherapists would prefer more flexibility. Regarding the 'high muscle strength subgroup', both patients and physiotherapists reported mixed feelings on the low number of supervised sessions, with some perceiving this low number as advantageous for stimulating the patient's own responsibility, whereas others as hindering an optimally guided treatment. Regarding the 'obesity subgroup' dieticians and physiotherapists acknowledged the added value of the combined intervention, but both were disappointed by the lack of interdisciplinary collaboration. Moreover, those patients in this subgroup already following a diet restriction, therefore not perceiving any added value of the diet intervention.

Conclusion: This qualitative study revealed relevant barriers and facilitators of our new model of stratified exercise therapy, which will help us interpreting the upcoming results on its (cost-) effectiveness [1]. If proven to be (cost-)effective, implementation strategies should specifically focus on guidance of patients from the "high muscle strength subgroup' within only a few sessions, collaboration between physiotherapist and dietician in the 'obesity subgroup', and adequate use of booster sessions after the supervised period to optimize treatment adherence.

\section{REFERENCES:}

[1] Knoop J, Dekker J, van der Leeden M, de Rooij M, Peter WFH, van Bodegom-Vos L, van Dongen JM, Lopuhäa N, Bennell KL, Lems WF, van der Esch M, Vliet Vlieland TPM, Ostelo RWJG. Stratified exercise therapy compared with usual care by physical therapists in patients with knee osteoarthritis: A randomized controlled trial protocol (OCTOPuS study). Physiother Res Int. 2020 Apr;25(2):e1819. doi: 10.1002/pri.1819. Epub 2019 Nov 28.

Disclosure of Interests: None declared

DOI: 10.1136/annrheumdis-2021-eular.1508 